\title{
Design and Development of GSM based Energy Meter
}

\author{
Abhinandan Jain \\ Department of Electronics \& \\ Electrical Communication \\ PEC University of Technology, \\ Chandigarh, India
}

\author{
Dilip Kumar \\ Department of Academic and \\ Consultancy Services Division \\ C-DAC, Mohali \\ Mohali, India
}

\author{
Jyoti Kedia \\ Department of Electronics \& \\ Electrical Communication \\ PEC University of Technology, \\ Chandigarh, India
}

\begin{abstract}
Traditional metering method for retrieving the energy data is not convenient and the cost of the data logging systems is high. So this paper presents of design and development of Automatic meter reading (AMR) system. AMR system is a boom for remote monitoring and control domestic energy meter. AMR system give the information of meter reading, power cut, total load used, power disconnect and tempering on request or regularly in particular interval through SMS. This information is being sent and received by concerned energy Provider Company with the help of Global system for mobile communication (GSM) network. Energy provider receives the meter reading within a second without visiting person. AMR minimize the number of traditional visits required by employs of energy Provider Company. This system not only reduces the labor cost but also increase meter reading accuracy and save hugs amount of time.
\end{abstract}

Key term: Short message service (SMS), Automatic meter reading (AMR), Energy meter, Energy provider company, GSM.

\section{INTRODUCTION}

An energy meter is a device which is used to measures the consumption of energy of any residence or other industrial establishment. In Conventional metering system to measure electricity consumption the energy provider company hire persons who visit each house and record the meter reading manually. These meter readings are used for electricity bill calculation and this bill sent to consumer house by post. This is only a sluggish and laborious. In Conventionally metering system people try to manipulate meter reading by adopting various corrupt practices such as current reversal or CT reverse tampers, partial earth fault condition, bypass meter, magnetic interference etc. There is a stark amount of revenue loss being incurred by our country. This metering system becomes very difficult especially in rainy season. If any consumer did not pay the bill, the electricity worker needs to go to their houses to disconnect the power supply. It is inefficient way for measuring power consumption. Power line communication and Zigbee technology also use for meter reading. The stability and reliability of meter reading data are low of power line communication because the carrier wave signal (power/telephone line) is very easily disturbed by noise [1]. The ZigBee devices are extremely limited in resources including processing, memory, and power, short operating range [2]. GSM based automatic meter reading system is a succor. AMR eliminates any possibility of electricity theft.

Automatic meter reading (AMR) system is an effective way of data collection, that allow substantial saving through the reduction of meter read, greater accuracy, allow frequent reading, improved billing, reduced tempering. It provides better customer services, by sending alert of power cuts and consummation updates [3]. AMR is the technology for remote monitoring and to control domestic energy meter and reduces current pilfering. This paper presents a network communication technology which enables energy Provider Company to read the meter reading regularly without the person visiting each house by using GSM communication technology. AMR system is very useful for remote area or small villages which are not connected by any means of transport such as an island or remote precinct. This GSM based data collection system can be very swift, accurate and efficient.

\section{SYSTEM DESCRIPTIONS}

Figure 1 shows the complete system description. In this system each and every meter is provided a particular ID number. This ID number is provided according to SIM card unique service number. This system continuously monitors every meter reading daily, weekly, monthly or on request and sends to central server of energy Provider Company. The meter reading is stored in database server through SMS gateway. After billing calculation a bill is issued by energy Provider Company which can be sent either by email, by web account or by post. Customers can pay the bill using net banking. AMR also sends the information of power cut and power consumption through SMS. This SIM card service number is used to identify and retrieve customers detail for billing and identification purpose.

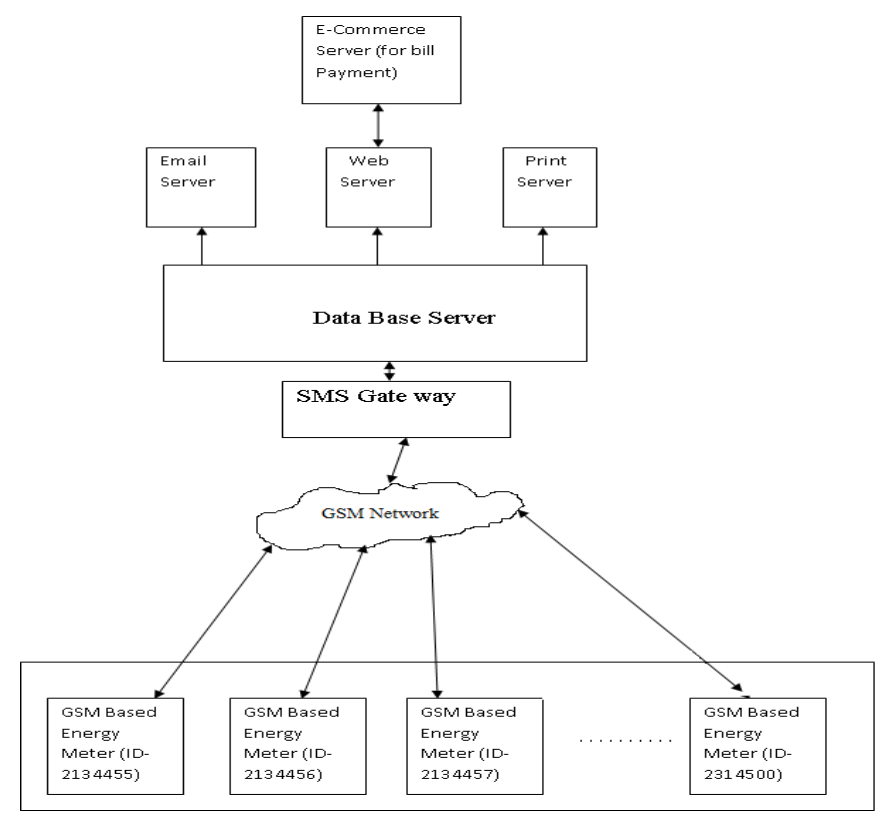

Fig 1: Overview of GSM based AMR system 


\section{TECHNICAL SPECIFICATIONS}

Table 1 shows the technical specification of GSM based energy meter. These systems are used for remote monitoring of energy meter. This system also can be used to disconnect the power supply to the house in a case of nonpayment of electricity bills/ have large outstanding dues. This system give the information of power cut in particular area and power cut time so this feature is useful for remote areas. A temper detection unit also connects with the meter so there is no possibility of tempering. If tempering occurs then tempering unit will be activated, and a SMS is automatically send to central server of the energy provider company that cut the power of that house. So, In AMR tempering is not possible.

Table 1. Shows the technical specification of GSM based energy meter

\begin{tabular}{|c|c|c|}
\hline $\begin{array}{l}\text { Sr. } \\
\text { No. }\end{array}$ & Parameter & Specification \\
\hline 1. & Operating voltage & $240 \mathrm{~V}$ \\
\hline 2. & Operating frequency & $50 \mathrm{~Hz}$ \\
\hline 3. & Pulses & 3200Imp/KWh \\
\hline 4. & GSM modem & $\begin{array}{l}\text { Tri band GSM modem } \\
\text { (GSM900/1800 MHz) designed } \\
\text { for data SMS. }\end{array}$ \\
\hline 6. & Power cut alert & $\begin{array}{l}\text { This system provides power cut } \\
\text { information. }\end{array}$ \\
\hline 5. & $\begin{array}{l}\text { Automatic reading } \\
\text { feature }\end{array}$ & $\begin{array}{l}\text { It can be remote monitoring and } \\
\text { controlling anywhere in the } \\
\text { world. }\end{array}$ \\
\hline 7. & $\begin{array}{l}\text { Auto disconnect } \\
\text { feature }\end{array}$ & $\begin{array}{l}\text { It provides remote shut-off } \\
\text { facilities to customers that have } \\
\text { large outstanding dues. }\end{array}$ \\
\hline 8. & $\begin{array}{l}\text { Auto reconnect } \\
\text { feature }\end{array}$ & $\begin{array}{l}\text { It can be reconnect the power } \\
\text { supply after pay outstanding } \\
\text { dues. }\end{array}$ \\
\hline 9. & Total load calculation & $\begin{array}{l}\text { This system gives information } \\
\text { of total load used in particular } \\
\text { house at any time to energy } \\
\text { provider company through } \\
\text { SMS. }\end{array}$ \\
\hline 10. & Full secure & $\begin{array}{l}\text { If any person trying to access } \\
\text { the system then it sent a SMS } \\
\text { alert to energy provider } \\
\text { company for this. }\end{array}$ \\
\hline 11. & Temper proof feature & $\begin{array}{l}\text { Tempering unit used if } \\
\text { tempering occurs and it sends } \\
\text { SMS alert to the energy } \\
\text { provider company. }\end{array}$ \\
\hline 12. & Memory & $\begin{array}{l}\text { Non-volatile based energy } \\
\text { reading system. }\end{array}$ \\
\hline 13. & Display system & $\begin{array}{l}\text { LCD display system used for } \\
\text { energy display, real time \& } \\
\text { date, instantaneous active load } \\
\text { in kilowatt. }\end{array}$ \\
\hline
\end{tabular}

\section{DESIGN OF AMR}

Figure 2 shows a block diagram of AMR. AMR Continuously monitor and record the energy meter. This can be achieved by using microcontroller. Figure 2 show that microcontroller unit is interface with energy meter and LCD. Microcontroller unit continuously monitor the energy meter and pulses display on LCD. That's give the information of power consumption in a house. For the information of power cut microcontroller unit is interface with RTC clock and relay. For communication purpose microcontroller unit is also interfaced with GSM modem by using MAX 232.

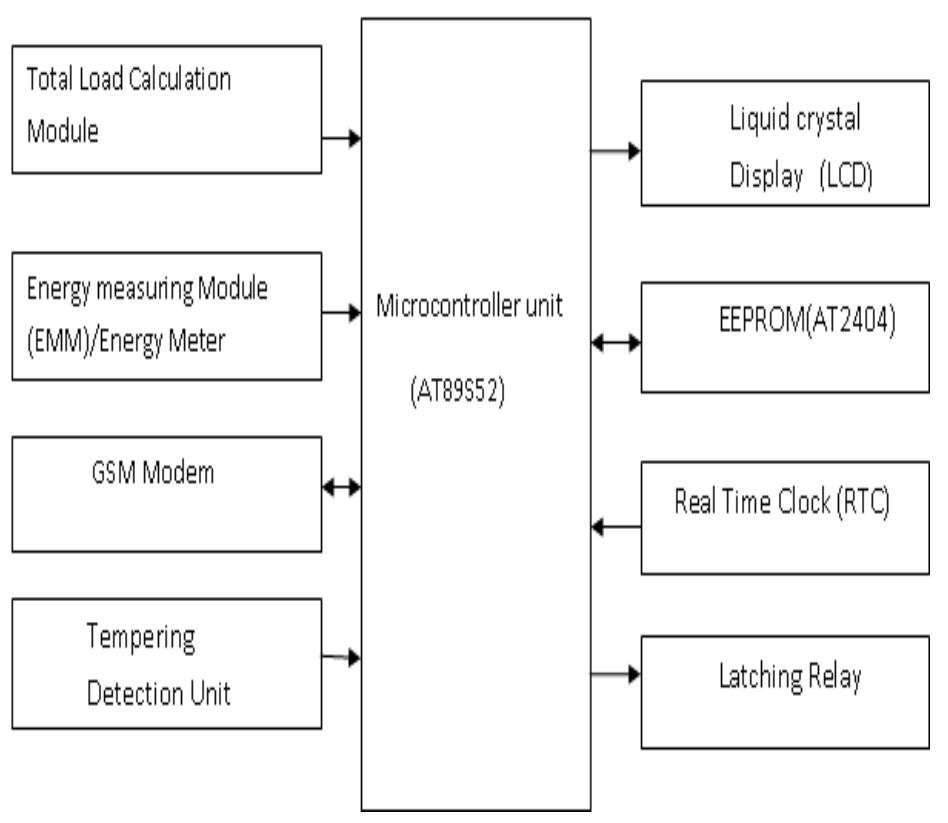

Fig 2: Block diagram of GSM based automatic energy meter reading system [4]

\subsection{Microcontroller unit}

Microcontroller unit is used for controlling of complete AMR system. The AT89S52 is a low-power, high-performance CMOS 8-bit microcontroller with $8 \mathrm{~K}$ bytes of in-system programmable flash memory. The AT89S52 provides 256 bytes of on-chip RAM $8 \mathrm{~K}$ bytes of flash Memory, $32 \mathrm{I} / \mathrm{O}$ lines, watchdog timer, two data pointers, three 16-bit timer/counters a full duplex serial port, on-chip oscillator, and clock circuitry.

\subsection{Energy measuring module}

Energy measuring module continuously measuring the instantaneous voltage and current and finding the product of these to give instantaneous electrical power. It is spout the power in the form of pulses and also give the information of power on and off status. This data are display on to the Liquid crystal display.

\subsection{Real time clock}

In this project DS1307 serial real time clock is used for giving the information of date and time of power cut. DS 1307 have 56 bytes RAM. Address and data are transferred serially by 2 wire, bi-directional bus. The clock/calendar provides seconds, minutes, hours, day, date, month, and year information. The DS1307 has a built-in power sense circuit that detects power failures and automatically switches to the battery supply.

\subsection{Relay section}

Relay circuits are interfaced with the energy meter and microcontroller. Relays allow one circuit to switch a second 
circuit which can be completely separate from the first. Relay circuit are used for switching the consumer's main consumption line between cut-off and power supply mode. It is proved to be very helpful feature for energy provider company, who can remotely switch into cut off mode from power on mode of any consumer due to nonpayment of electricity bills / has large outstanding dues. it can reconnect the power supply after payment of dues.

\subsection{Liquid crystal display}

A Liquid crystal display are interfaced to microcontroller unit that are used to display the meter reading, date time, power factor, power status, total load used etc.

\subsection{Data storage unit}

AT24C04 is electrically erasable programmable read only memory is used for the data stored in its $4 \mathrm{~KB}$ Memory. EEPROM interfaced with the microcontroller by using 2 wire serial interfaces. If power cut off the content of RAM must be stored in EEROM, and when power will be back the energy meter will be start from its previous state [4].

\subsection{Temper detection unit}

Today energy theft is a serious problem due to energy theft heavy revenue losses are incurred by country. A tempering unit used for stop of this energy theft that sent the alert to energy provider company when tempering occurs. If any person tries to tempering (such as current reversal or CT reverse tampers, partial earth fault condition, bypassing meter, magnetic interference, phase or neutral wire swapped, external tempers etc.) with energy meter the tempering unit will be activated and as SMS alert send central server of the energy provider company.

\subsection{GSM modem}

Quad-band intelligent GSM/GPRS modem suitable for long duration data transmission. To implement AMR system a GSM modem is connected to a microcontroller which would transmits data from a meter to cell phone and also receive commend from cell phone to energy meter. The modem will send unit or pulses (power consumption) on a regular interval or on a request. AT commands set which stands for attention terminal are used by energy meter to communicate with the GSM Modem.

\subsection{Total load calculation}

AMR also give the information of total load used in a house on request at any time. Total load used in any house can be calculated by observed or record $\mathrm{N}$ number of pulse in $\mathrm{T}$ time that is described by equation number 1 .

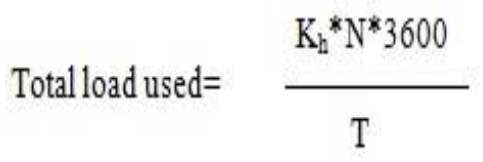

Where

$$
\begin{aligned}
& \mathrm{K}_{\mathrm{h}}=\text { Meter constant } \\
& \mathrm{N}=\text { Number of pulse } \\
& \mathrm{T}=\text { Total pulse time of } \mathrm{N} \text { pulses }
\end{aligned}
$$

Energy meter also sends a SMS alert to the energy provider company and customers if any persons used more than specify limit of load. The energy provider company can disconnect the power of respective customer. So customers manage their house power consumption.

\section{FLOW DIAGRAM OF THIS SYSTEM}

Figure 3 shows that energy meter continuously display the pulse and unit according power consumption. When Energy provider company requires data for calculation of bill so they send a message to AMR.

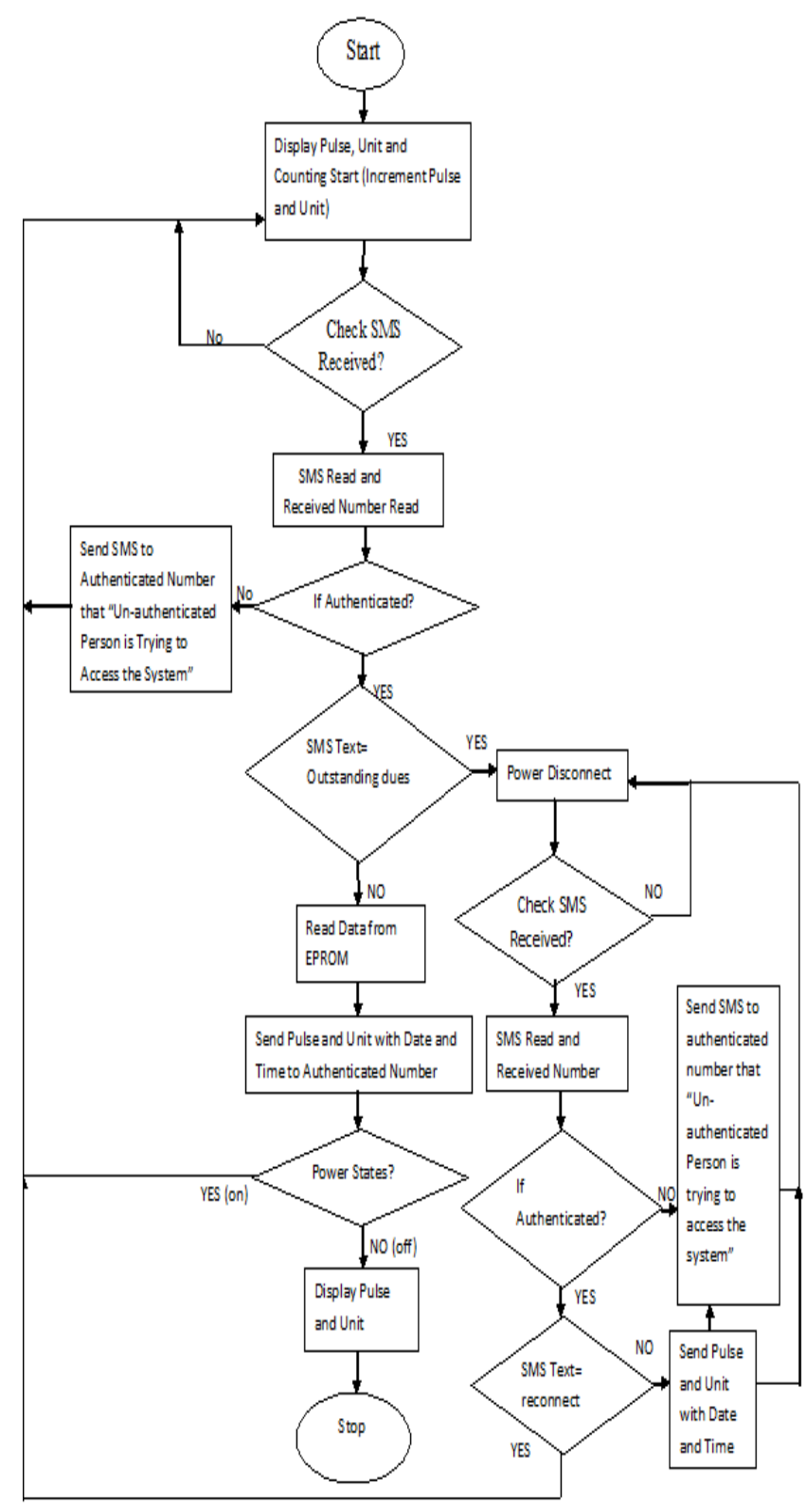

Fig 3: Flow diagram of controlling program for AMR

So, microcontroller unit receive a message and it read this message and also read user mobile number and check the authentication. If the number is authenticate; it read current data from EEPROM and sends the data to authenticated number. If system access mobile number is not authenticated; GSM based AMR sends a SMS alert to energy provider. It also provides the facility of power disconnect to customer that have large outstanding dues by sending a code to the energy meter. Microcontroller has a program of matching of this code to power disconnect code. If this code is match then power disconnect to respective meter. It also provides a facility to power re-connect due to deposit the outstanding previous bill amount by sending a code to the energy meter. 
Microcontroller has a program of matching of this code to power re-connect code. If this code is matches then power reconnect to respective meter. Power cut feature perform by using interrupt signal.

\section{IMPLENTATION AND RESULTS}

Figure 4 shows the prototype modal of GSM based energy meter. In this project the pulse and unit (meter reading) count continuously according to load connected. Accordance to their demand of meter reading energy provider company send a SMS to the respective meter. Microcontroller receives this SMS through GSM modem so an interrupt signal occurred due to SMS. Microcontroller read pulse and unit from EEPROM and send the same to authorized number.

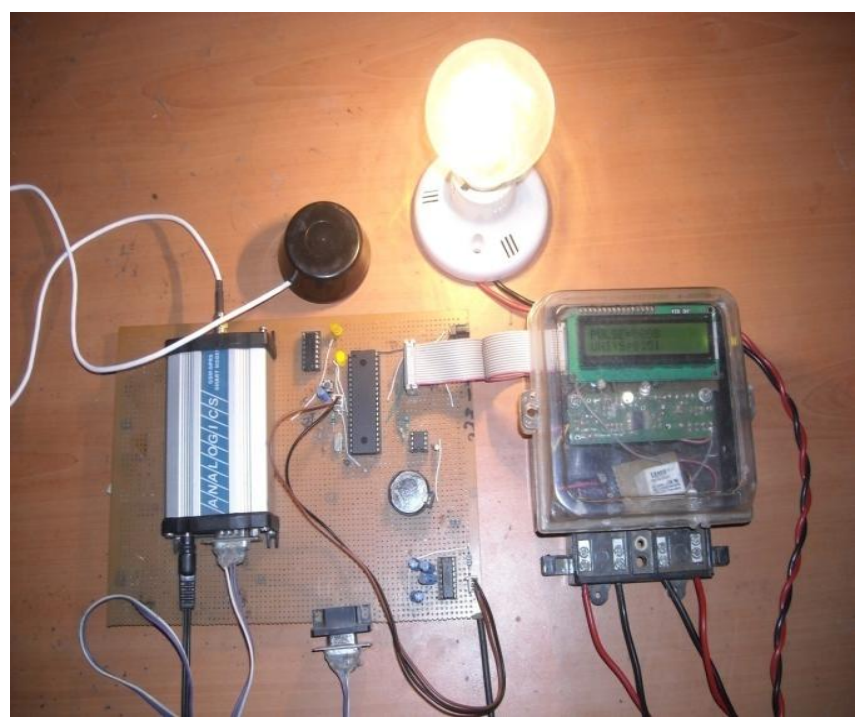

Fig 4: Prototype modal of GSM based energy meter

Figure 5 shows the product type GSM based AMR when power status on. The design of product follows all three aspect aesthetic design, engineering design, and ergonomic design.

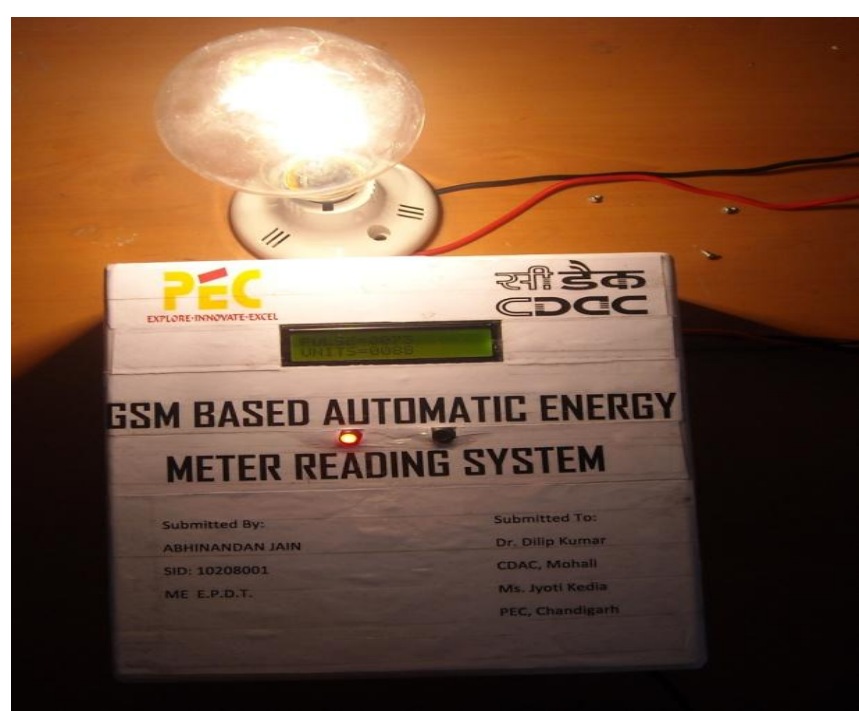

Fig 5: Product type GSM based AMR

Figure 6 shows the meter pulse and unit detail in mobile that is sending by AMR system to energy provider company. After proper reckoning energy provider company will send a notification to customer either by e-mail or by post. The customer can pay online through the net-banking or credit card. Figure 7 shows the important feature of this system is that, this system gives the information of power cut. If there is a power cut in particular area AMR send a SMS to energy provider company about the power cut. In case of power cut AMR is working by rechargeable battery.

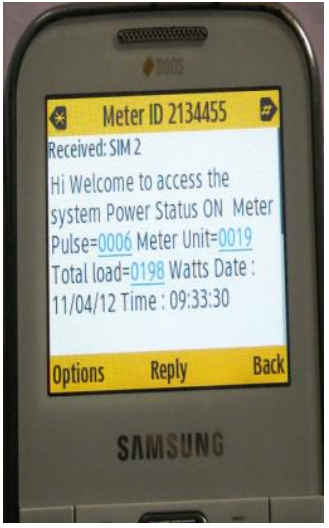

Fig 6: Meter pulse and unit received at energy provider authorized number

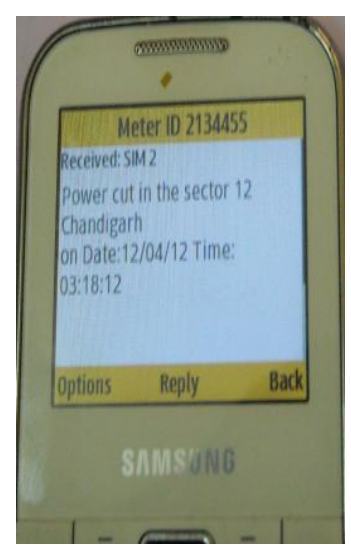

Fig 7: Power cut alert received at energy provider authorized number
Figure 8 shows another feature of this system disconnects the power of customer house which are fail to make payment of previous some month. In this case SMS will be sent to customer and energy provider that "Power of Meter has disconnected duo to outstanding dues on Date: 14/04/12 Time: 11:28:56". If customer pays the bill, his connection will reconnect. All this cumbersome process is happening with the help of relay.

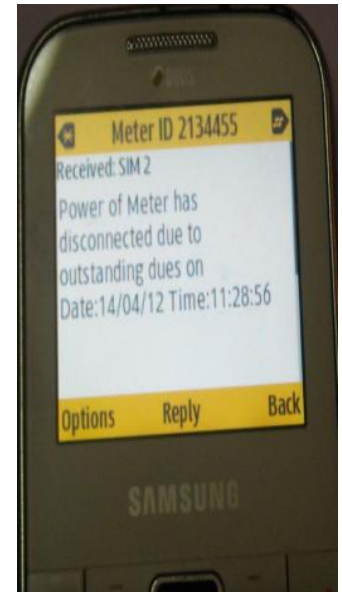

Fig 8: Power disconnect alert received at energy provider authorized number

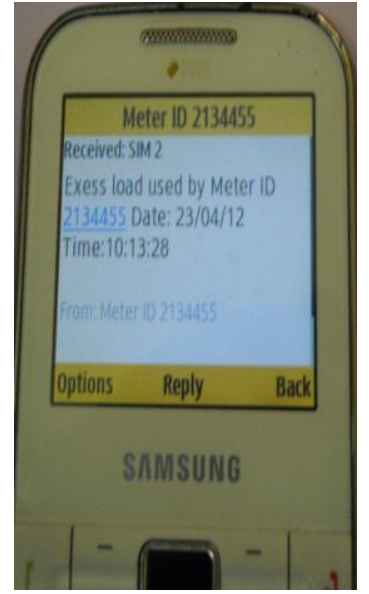

Fig 9: Excess load alert received at energy provider authorized number
Figure 9 shows total load used alert feature of this system in a house. Energy meter sends a SMS alert to energy provider company whether people using more than specify limit of load in such format "Excess load use by METER ID 2134455 Date: 23/04/12 Time 10:13:28". Energy provider also gets the information of power load at any time. Last but not the least important feature of this system is that it gives the information of tempering, if any person attempts to temper energy meter, then a signal will be active and AMR will sent a SMS to energy provider company that "Tempering occurs on Meter 
ID $2134455 \%$. Energy provider company connections will be cordoned off of this meter without visiting site.

\section{CONCLUSION}

GSM based energy meter is easy to installation and beneficial for both energy provider and consumer. AMR is not only solve the problem of manual meter reading but also provide additional feature such as power disconnect due to outstanding dues, power reconnect after pay dues, power cut alert, tempering alert. AMR also gives the information of total load used in a house on request at any time. It sends a SMS alert to energy provider company whether a person using more than specify limit of load. The statistical load used and profile can help customer manage their energy consumption. This system is secure and reliable because it can be accessed only by an authorized person. If any un-authorized person tries to access the system this system send an alert to energy provider and also give warning of that unauthorized person. This device has the capability to revolutionize the energy meter market and will become help to country revenue by stopping the current theft and punishing the dishonest customers.

\section{REFERENCES}

[1] Dr. Mohd Yunus B Nayan1, Aryo Handoko Primicanta 2009. Hybrid System Automatic Meter Reading. International Conference on computer technology and Development,(ICCTD -09), pp: 264-267.

[2] Kwang-il Hwang 2009. Fault-tolerant ZigBee-based Automatic Meter Reading Infrastructure. Journal of Information Processing Systems, Vol.5, No.4, pp:221228.

[3] H.G.Rodney, Tan IEEE, C.H.Lee and V.H.Mok, 2007. Automatic Power Meter Reading system using GSM Network. The 8th International Power Engineering Conference, pp: 465-469.

[4] Md. Wasi-ur-Rahman, Mohammad Tanvir Rahman, Tareq Hasan Khan and S.M. Lutful Kabir 2009. Design of an Intelligent SMS Based Remote Metering System. IEEE International Conference on Information and Automation, pp: 1040-1043.

[5] Huibin sui, Honghong Wang, Ming-Shun Lu and WeiJen Lee 2009. An AMI System for the Deregulated electricity Markets. IEEE Transaction on Industry Application, pp: 1-5.

[6] Liting Cao Jingwen Tian Yanxia Liu 2008. Remote Wireless Automatic Meter Reading System Based on Wireless Mess Networks and Embedded Technology. Fifth IEEE International Symposium on Embedded Computing, pp: 192-197.

[7] Bharath P, Ananth N, Vijetha S, Jyothi Prakash K. V. 2008. Wireless Automated Digital Energy Meter . IEEE International Conference on Sustainable Energy Technologies, pp: 564-567.

[8] W. Amer, Y. Attique, A. Nadeem, Abdul Ghafoor 2010. Comprehensive e-monitoring, e-management andebilling $\left(\mathrm{eM}^{2} \mathrm{~B}\right)$ System with ZOOM-in ZOOM out Capabilities to Reduce Electricity Distribution Losses for Developing Countries. $4^{\text {th }}$ IEEE Annual system conference, pp: 174-177.

[9] Syed Shahbaz Ali, Madiha Maroof, Sidrah Hanif 2010. Smart Energy Meters for Energy Conservation \& Minimizing Errors. Joint International Conference on Power Electronics, Drives and Energy Systems (PEDES) \& Power India, pp: 1-7.

[10] Yong Hoon Lim, Moon Suk Chai, Jong Mock Baek, Sang-Yeom Lee 2011. An Efficient Home Energy Management System Based on Automatic Meter Reading. IEEE International Symposium on Power Line Communication and Its Applications, pp: 479-484. 